\title{
ESTIMULANDO 0 DEBATE SOBRE A GESTÃO ESTRATÉGICA DE PESSOAS
}

\author{
Por Lindolfo Galvão de Albuquerque \\ Professor da Faculdade de Economia, Administração e Contabilidade, Universidade de São Paulo - SP, Brasil
}

\section{Nildes Pitombo Leite}

Professora do Programa de Pós-graduação em Administração, Universidade Nove de Julho - SP, Brasil

\section{Leilianne Michelle Trindade da Silva}

Doutoranda em Administração pela Faculdade de Economia, Administração e Contabilidade, Universidade de São Paulo - SP, Brasil

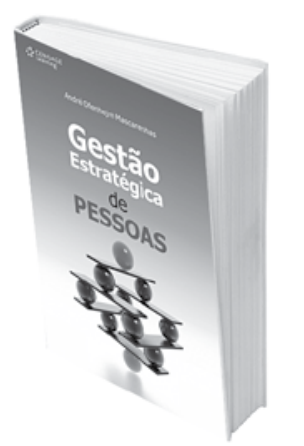

\section{GESTÃO ESTRATÉGICA DE PESSOAS - EVOLUÇÃO, TEORIA E CRÍTICA}

De André Ofenhejm Mascarenhas

São Paulo: Cengage Learning, 2008. 303 p.

A base crucial, presente no livro de André Ofenhejm Mascarenhas, é a inquietação crítica acerca de pressupostos, comprometimentos, prioridades e fronteiras que podem permear um debate sobre gestão estratégica de pessoas. Para o intento de tal debate, o autor adverte que a apropriação seletiva de referenciais teóricos de outras subáreas, em Administração, tais como comportamento organizacional, teoria das organizações e estratégia, deverá ser pensada em termos de suas implicações para a gestão de pessoas.

A gestão estratégica de pessoas é contemplada, nessa obra, em seus fundamentos, suas abordagens, atuação, críticas e temas contemporâneos, dos quais decorre o subtítulo do livro, "Evolução, teoria e crítica”. As subáreas comportamento organizacional, teoria das organizações e estratégia - são revisitadas e tornam fecundo o diálogo so- bre a gestão estratégica de pessoas, em sua essência e complexidade, ao longo do desenvolvimento do livro.

A obra está estruturada em três grandes partes que se desdobram, evidenciando a sucessão de teorias, críticas e proposições em gestão estratégica de pessoas. A primeira aborda a gestão estratégica de pessoas como alinhamento sistêmico. A segunda, como potencial competitivo. A terceira, em seus temas contemporâneos.

De forma geral, a ideia de evolução trazida pelo livro indica que os primórdios da gestão estratégica de pessoas estariam associados ao que o autor se refere como paradigma de adequação indivíduo-cargo, que remete aos princípios difundidos pela teoria clássica da Administração. Tal paradigma se restringia à busca do alinhamento entre as tarefas de responsabilidade de determinadas posi- ções hierárquicas e às qualificações e características necessárias das pessoas que ocupariam esses cargos.

Várias críticas surgiram em função do reconhecimento da abordagem limitada desse paradigma, dentre elas as oriundas da escola das relações humanas, que percebia a organização como um sistema social complexo, cujas interações não se restringiam às posições formais. Com a incorporação de tais críticas, a gestão estratégica de pessoas segue seu curso de desenvolvimento e se associa à noção de alinhamento sistêmico, evidenciando e popularizando o papel da gestão de pessoas para o alcance dos objetivos estratégicos de uma organização. Surge, assim, a abordagem contingencial, que considera a necessidade de alinhamento da gestão de pessoas a fatores de contingência, tais como o ambiente externo, a estratégia e a cultura organi- 
zacional, atribuindo, entretanto, uma condição passiva e uma direção linear de adequação do modelo de gestão de pessoas a esses fatores.

Nessa primeira parte, é contemplada a gestão estratégica de pessoas como alinhamento sistêmico, segundo as abordagens contingencial, universalista e cultural. A atuação do RH é questionada, com vistas à transformação necessária para a incorporação da estratégia. Por sua vez, a atuação estratégica do RH toma como ponto de partida o diagnóstico das condições de negócio, incorporando a ideia do planejamento estratégico de pessoas, com a responsabilidade de articulação com o processo de planejamento estratégico corporativo. Discute o planejamento tático no nível das atividades e dos processos de gestão de pessoas, acompanhando e avaliando as políticas de RH.

Finalizando a primeira parte, o autor traz as críticas - conceitual, empírica, cultural e prescritiva - aos pressupostos, conceitos e práticas associadas às proposições pioneiras de gestão estratégica de pessoas, nas quais são apontadas, respectivamente, as limitações conceituais, as dúvidas sobre efetividade empírica, as dificuldades práticas e a introdução de novos conceitos para a compreensão da evolução da gestão estratégica de pessoas.

O determinismo associado à ideia de alinhamento foi alvo de diversas críticas prescritivas, uma vez que limitava a contribuição da gestão de pessoas e ignorava o seu potencial de gerar vantagem competitiva para as organizações. A partir dessas críticas, a gestão estratégica de pessoas evolui para o que o autor se refere como o paradigma do potencial competitivo, recebendo influência da teoria dos recursos e das noções de competências essenciais e capacidades dinâmicas. $\mathrm{O}$ papel da gestão de pessoas transcende as barreiras da simples implementação de estratégias e assume a responsabi- lidade compartilhada pela formulação das estratégias organizacionais, num processo dinâmico de geração de configurações de recursos e competências únicas, que, por sua vez, precisam ser articuladas por configurações de estratégias, políticas e práticas de gestão de pessoas, particulares para cada organização.

Abrindo essa parte da obra, o autor passa a revisitar a teoria dos recursos, com base nos recursos propriamente ditos e, também, nos conceitos de competências, capacidades dinâmicas da empresa e aprendizagem organizacional. Com isso, principia a apresentação do tema "vantagem competitiva e gestão de pessoas". Prosseguindo, ele se volta para uma reconceitualização do modelo de gestão estratégica de pessoas, com ênfases revigoradas: dos comportamentos às competências; do alinhamento estratégico à flexibilidade organizacional; das culturas organizacionais fortes à diversidade cultural. Finalizando essa parte, o autor sugere que a direção do debate está voltada para a necessidade de repensar a estrutura e as funções estratégicas da área de RH.

A terceira parte da obra traz os temas contemporâneos em gestão estratégica de pessoas. O autor dedica capítulos a: gestão das competências, individual e organizacional, consideradas estratégicas para a organização; gestão das mudanças, delineando um modelo de gestão compatível com uma visão dialética da organização; gestão e avaliação de resultados em gestão de pessoas, ou a necessidade de acompanhamento, mensuração e avaliação do impacto das práticas de RH no desempenho organizacional; gestão da diversidade, associada à aprendizagem organizacional e à noção de organização pluralista; sistemas de informação em gestão de pessoas e sua contribuição para a reestruturação da gestão de pessoas.

Diante do exposto, percebe-se que o autor traça o caminho da evolução do campo da gestão estratégica de pessoas sempre descrevendo as teorias que fundamentaram o desenvolvimento de suas ideias e expondo as críticas que foram responsáveis pela passagem de um patamar a outro ao longo do tempo.

Como afirmado pelo próprio autor, "esta obra traz uma interpretação (certamente não exaustiva) da evolução dos conceitos, teorias e críticas em gestão estratégica de pessoas" (p. XV). Tal afirmação encerra cuidados, alertas e, sobretudo, um instigante convite à perene reflexão sobre as implicações das ideias, em gestão estratégica de pessoas, para a prática organizacional, o que certamente assegurará a continuidade do debate proposto.

É um livro que se diferencia dos demais na forma abrangente de apresentação da evolução histórica do campo, situando os leitores menos familiarizados com a área e proporcionando uma visão geral sobre a maneira como a temática surgiu e como se encontra o patamar atual de desenvolvimento. Nesse aspecto, ele se torna um livro atraente, especialmente para o público acadêmico, sem distinção de nível, envolvendo professores e estudantes de graduação e pós-graduação - lato e stricto sensu.

Outra característica marcante da obra é a postura crítica assumida ao longo de todo o texto. A leitura não se restringe à passividade, mas desperta, a todo momento, a reflexão em função dos pontos e contrapontos apresentados continuamente pelo autor.

Desse modo, o livro traz grandes contribuições para a formação de pesquisadores na área, com novas ideias e perspectivas para perenizar o debate.

Por outro lado, o conteúdo do livro não se mostra de fácil aplicação no meio organizacional, seja pela forma acadêmica de redação, seja pela própria complexidade do assunto. 